\title{
Geo-Cultural Influences and Critical Factors in Inter-firm Collaboration
}

\author{
By \\ Helen Lawton Smith \\ Local Economic Development Unit, \\ Coventry Business School, \\ Coventry University, \\ Priory Street, Coventry CV1 5FB, UK \\ $\&$ \\ Keith Dickson \\ Brunel Business School, \\ Brunel University, \\ Uxbridge, UB8 3PH, UK
}

Published in

International Journal of Technology Management, 25(1/2):34-50, 2003

\begin{abstract}
:
Inter-firm collaboration and other forms of inter-organisational activity are increasingly the means by which technological innovation occurs. This paper draws on evidence from two studies of the same set of firms to examine the conduct of collaborations over time across different contexts. The purpose is to examine the critical factors associated with successful collaboration and explore the importance of the geo-cultural context in understanding the conduct of inter-firm collaboration. The conceptual framework draws on two main sources: - Storper's concept of 'conventions' of identity and participation and Lorenz's classification of different types of knowledge. These are used to indicate the kinds and sources of adjustments required for successful collaboration.
\end{abstract}

Key words: Research, Collaboration, innovation, conventions, types of knowledge 


\section{Introduction}

Industrial firms are increasingly considering external technological acquisition in order to maximise their capabilities for further technological change. In The Changing State of British Enterprise, Moore reported that there is a positive relationship between the growth performance of small and medium sized enterprises and their propensity to acquire new technologies externally [1]. Moreover, acquisition of new technologies was more likely to be from other firms than from institutions such as universities. This paper focuses on a particular form of acquisition of new technologies from other firms - that of inter-firm collaboration. The paper uses evidence from two studies of the same set of collaborating firms five years apart [2,3] to examine the conduct of collaborations over time across different contexts.

The firms in these studies, like research and development intensive firms in general, operate on a number of geographical scales, ranging from local to international levels. In industries characterised by high levels of innovation there is no option for large and small firms but to compete and collaborate at the international scale $[3,4,5]$. Collaboration as a form of commitment operating at different spatial scales creates what Swyngedouw [6] has called changing 'sociospatial relationships' in which new arrangements embody a set of power relations and norms of co-operation. Moreover, it facilitates the geographical re-organisation of innovation as firms' collaborative activities move from one spatial scale to another.

The argument developed examined here is that collaboration is shaped by a series of geographically specific context dependent critical factors. These cultural factors can influence, and are influenced by, firms' capacity to learn to collaborate with firms in their own country and with firms in other countries. The geo-cultural contexts in which firms are based create their own set of expectations about the rules of behaviour governing the conduct of the collaboration and of the risks attached to different activities. We examine some of the problems firms have to overcome in collaboration as a result of national differences. 
The conceptual framework draws on two main sources. These are Storper's [7] concept of 'conventions' of identity and participation, and Lorenz's [8] classification of different types of knowledge. These are used to indicate the kinds and sources of adjustments required for successful collaboration. The former takes account of how the geographical context is involved in shaping of the conduct of inter-organisational activity, while the latter helps to identify the cultural content of interaction.

The rest of the paper is in five sections. The first examines the increasing range of interorganisational interactions which comprise the general tendency towards externalisation of innovation, which reflects a more general trend of externalisation within the production process [9]. The second focuses on the different kinds of learning which underpin collaboration. The third identifies some of the features of national and international contexts which influence patterns of interaction. The objective is to identify which aspects of national context matter compared to more general problems associated with the innovation process. The fourth uses case study material to examine the conduct of collaborations over time. The final section provides some conclusions.

\section{Collaboration and Acquisition of New Technology}

Innovation has been defined as, "the processes by which firms master and get into practice product designs and manufacturing processes that are new to them, if not to the universe or even to the nation" [10]. Collaboration is one form of this process and is based on the use of "complementary assets' [11], such as technology and market access. It has a multiplicity of co-operative forms but which have two defining characteristics:- co-operation, and frequent interaction. Collaborations involve a greater or lesser degree of interdependency and trust [12]. Some are self-regulated collaborations in which formal terms are agreed by the collaborating firms, and others are institutionalised arrangements under national and international R\&D programmes where the rights and duties of participants are set out as part of the agreement to collaborate. Collaboration encompasses a range of activities including:

* Informal arrangements or 'loose couplings' initiated for specific problem solving [13];

* Production orientated close user-supplier relationships [14, 15]; 
* Formal, inter-firm collaboration for new product development $[2,16]$;

* Long-term strategic alliances for significant technological advances [17];

* Research links with universities and national laboratories [18, 19].

When things go well both participant firms engage in a learning process [15, 2021$]$. On the other hand, things often go wrong as innovation itself is inherently uncertain and risky. Collaboration introduces extra risks, requires extra resources, is hampered by information asymmetries and communication difficulties, and involves increased degrees of unpredictability [3]. A very high proportion of co-operative $R \& D$ ventures fail to meet expectations, so much so that losses incurred can adversely affect the profitability of one or more partner [22]. A survey of European firms found that many see co-operation with another firm as a high risk venture requiring detailed legal safeguards [23]. There are also sensitive issues for small firms who collaborate with larger partners and include fear of take over, maintaining control over know-how, and difficulties in finding suitable partners $[24,25]$. As different power relations are in play, the process of collaboration therefore may require longer term re-adjustment of organisational behaviour [22], in which allocations of financial and personnel resources are devoted to sustaining them and to protecting firms' interests.

Arising from several studies of inter-firm collaboration [2, 3, 5], it is possible to summarize a set of critical factors than influence the success of inter-firm collaborations. They are presented below (Table 1) as a pre-curser to the consideration of wider geographical contextual concepts by which they may be mediated. Further reflections on their significance are outlined in the main findings and evaluation sections. 


\section{Table 1: Critical Factors in Successful Collaboration}

\section{Compatibility:}

Corporate style and internal knowledge systems affects firms' ability to collaborate.

Control:

Firm need to feel they can exert adequate control over a proposed project.

Commitment:

Collaboration requires support from senior management in both firms.

Contractual Arrangements:

Within a formal agreement, some flexibility is necessary to sustain informal operations.

\section{Communications:}

The need for open and regular communications which can lead to increased trust and reciprocity

\section{Common Aims:}

Well defined and agreed at the outset.

\section{Contingencies:}

Appropriate arrangements need to in place to accommodate changing circumstances.

Context:

Firms need to recognise national differences, eg, in regulations, culture, social behaviour and organisational practices.

Conclusion:

Each firm possesses clear expectations of the project's outcome.

\section{Conceptual Issues Relating to Geographical Context}

The purpose here is to discuss the causality between geographical (local/national) context as an 
explanatory variable for understanding the conduct of collaboration. Other studies have focussed on the regional context to innovation. This is encapsulated in the view expressed that the world is composed of a, "hierarchical mosaic of densely-developed regional economies with specific resource endowments, assets, institutions, co-ordination mechanism, know-how, rules of conduct and cognitive frameworks" [26]. At the same time there has been a return to the recognition of the importance of national regulatory frameworks over local institutions, in providing the framework for industrial practices including the incentives to co-operate $[27,28]$.

The first stage is to identify how geo-cultural context influences the conduct of collaboration. We begin with Storper's concept of conventions which emphasises the behavioural basis of inter-firm transactions which lead to technological learning at the local level [7]. He argues that if the behaviours of producers and users - their expectations, preference structures, and so on - differ considerably from place to place, it stands to reason that certain types of behavioural routines, and the rules and institutions that underlie them, are more effective at promoting interactions which sustain technological learning than others. He identifies the key principles of mutual engagement of critical agents in the production system as conventions of identity and participation that production system and its agglomeration. Conventions are practices, routines and agreements, and their associated informal or institutional forms. They amount to a set of acknowledged and shared rules [28]. These acquired practices which have a new cultural identity bind economic actors together so that mutual behavioural expectations co-ordinate their activities. In essence, such a set of conventions defines a local 'world of production'. Gertler points out that Storper places considerable emphasis on the importance of shared conventions for facilitating technology-based communication and learning through interaction, and the positive role that shared cultural attributes will exert on this process [28].

The same logic used by Stopper to explain the behavioural bias of learning in different regions can be used to explain the progress of inter-firm collaboration for innovation at different spatial scales. This is because of differences in conventions at the national as at the local level incorporate, amongst other things, cognition and rules [7]. The development of a successful collaboration will in effect involve the formation of a convention of identity and participation in the form of a commitment between two, and sometimes more, firms. 
To go further into the issue of learning and how firms adapt to working with others, we turn to Lorenz's identification of three types of knowledge which in collaboration contribute to a common cultural base [8]:

1. Common language - shared language, identity

(a pre-condition for the following, other two)

2. Common technical knowledge; e.g., knowledge of same computer system or software architecture, or shared techniques in biotechnology research)

3. Common organisational knowledge; ie, compatibility in terms of how firms are internally structured or organised).

The cultural base of the first can be region or nation specific, whereas the second and third, as alluded to earlier, can be sector or organisational specific.

To these kinds of knowledge we add two others. These are:

4. Common market intelligence

5. Common understanding of regulatory processes - regulations, standards and innovation support systems.

The fourth refers to a collective understanding of the way the market operates in different places. A common expectation between firms of what is necessary to compete is an essential component of collaboration. Thus firms wishing to enter or expand their presence in particular markets through collaboration need first to learn from their partner what is necessary to service customers in that market. Small firms can fall into the trap of being technology driven and develop products that are over-specified and too expensive for what can be a limited market niche [3]. The fifth is particularly important in international collaborations where each partner's domestic regulatory environment differs. Moreover, it cannot be assumed that firms in different countries will view compliance with international regulations from the similar perspectives or with the same intensity. Storper's interest was in locally-constructed behaviour. We now discuss the difference that the national context makes, providing illustrations of national characteristics of institutional, organisational and cultural identities:-

1. The geographical construction of sectors and their markets, and the relative concentration or fragmentation of those sectors.

- $\quad$ Countries have sectoral strengths and weaknesses which tend to persist over time. 
This is related to several inter-dependent factors including the propensity of sectors to innovate, national investment in scientific and industrial research, the size of the market, and the nature of domestic competition $[10,29]$. The necessity and possibility of international collaboration is linked to increasing national technological specialisation. International collaboration is not to replicate research in sectors where the home country is already strong, but to acquire know-how which is lacking at home [30].

- $\quad$ One of the UK's most innovative and collaborative industries is the pharmaceutical industry [31]. This pattern is related to specialisation within the science base nationally and institutionally, and the pattern of purchasing by the national health service.

- The size distribution of firms by country and sector, and relative dominance of large firms affect the structure and sets of relationships within national innovation systems. In France, for example, small firms have a limited role as active players in the innovation system [32].

2. Prevailing business cultures and the capacity of firms to both interact and absorb externally developed technology [32] are determined within the national production system.

- $\quad$ Several studies [34] have proposed that Anglo-American business culture and practice inhibits co-operation. It would appear that even in the late 1990s the historical pattern of production in British industry (ie, organised into separate firms dealing with each other at arm's length) still persists [35].

- Walker sees the UK as being characterised by a lack of 'collective integration' with respect to the integration of scientific and technological communities, as well the organisation of $R \& D$ and product development, banks and industry [36]. In contrast, the German national institutional framework can help substantially in solving the relational problems of high-quality incremental innovation, which require an environment in which long-term co-operation between firms, research institutes and university departments is facilitated. The US/UK institutional framework, it is argued, does not provide this [37]. 
3. The propensity for radical innovation in newly emerging sectors.

- $\quad$ Soskice [37] argues that, whereas the UK and the US are economies in which new industries are easily developed (eg, e electronics, biotechnology and new materials), Germany, Sweden and Switzerland are strong in incremental product and process innovation in established technologies.

4. Where technological advance is shaped by particular attributes of the national system of innovation, and institutionalised national bases of competition are produced by the regulatory environment.

- $\quad$ Market structures are influenced by procurement patterns (e.g. for defence and medicines), governments create ownership patterns (e.g. through privatisation of utilities and national laboratories as in the UK), organise the structure and function of the science base [18], affect sectoral profiles by preferential investment in different kinds of expertise (e.g. in national champions as in France), determine how intellectual property should be protected through the formulation of patent law, and establish the limits to competition between firms. For example the US/UK framework limits co-operation between companies via a strong competition policy [37].

- Other components of national institutional frameworks include patterns of shareholding, the banking system, legal system, education and training systems and the labour market $[28,37]$.

5. The nation state in the international environment. The nation state is becoming less dominant as some regulatory functions operate at the international level.

- While national standards predominate in some sectors, in others, even closely related ones, international regulation may be more important (eg, airports $\mathrm{v}$ airlines). Where standards vary between countries, firms may have to adapt their production strategies in order to collaborate and need to recognise the assumptions being made by their partner firm about product performance with regard to those particular standards. 
Taken together, these approaches can explain inter-firm collaboration as a learning process in which different types of knowledge are governed by rules of conduct and influenced by the geographical context. The concept of conventions and the typology of different kinds of knowledge identify what factors influence how well firms work together. Difficulties encountered in collaboration which serve to exclude or hinder the progress of collaborations with firms in other countries can be seen to arise from a failure to establish conventions of participation and to develop common knowledge. Firms not used to collaborating have to institutionalise into their business culture that knowledge acquired by key individuals who interact with other firms through their own networks. 


\section{Methodology}

The experiences of collaborating firms reported in this paper are drawn from two related studies on inter-firm collaboration whose samples are summarised in Table 2. In the first study, 27 pairs of collaborators were interviewed between 1988 and 1990 using semi-structured questionnaires[2]. The firms, comprising both large and small units, were known to be undertaking R\&D and engaged in collaboration through previous studies undertaken by the investigators. They were chosen as case studies in order to highlight interesting issues rather than as an attempt to provide representative examples of size of partners or of particular industries. The firms later took part in an evaluation exercise in which they assessed their own and their partner's contributions and expectations of the collaboration.

\begin{tabular}{|c|c|c|c|}
\hline \multicolumn{4}{|c|}{ Table 2: Summary of Samples of Collaborating Firms } \\
\hline Number of firms & Type of Partnership & Ownership & Sector \\
\hline \multicolumn{4}{|c|}{ Study 1: (1988-1990) } \\
\hline 27 pairs of firms & $\begin{array}{lr}5 & \text { small-small, } \\
16 & \text { small-large, } \\
5 & \text { large -large }\end{array}$ & $\begin{array}{l}\text { All firms UK-owned except: } \\
7 \text { large firms: ( } 3 \text { were US- } \\
\text { owned, and one each from } \\
\text { France, Canada, Netherlands, } \\
\text { and Japan). }\end{array}$ & $\begin{array}{l}\text { Biotechnology, } \\
\text { Electronic Instruments, } \\
\text { Mechanical Engineering, } \\
\text { Computer Software }\end{array}$ \\
\hline \multicolumn{4}{|c|}{ Study 2: (1994-1995) } \\
\hline $\begin{array}{l}18 \text { original firms } \\
+ \\
\text { two additional firms }\end{array}$ & \begin{tabular}{|l|}
6 ongoing collaborations \\
with original partners:- \\
5 small-large \\
1 small-small \\
2 collaborating with new \\
partners. \\
4 not collaborating \\
2 new collaborations \\
\end{tabular} & $\begin{array}{l}4 \text { large UK-owned, } \\
7 \text { small UK-owned, } \\
1 \text { large French-owned, } \\
3 \text { large US-owned } \\
1 \text { large Northern Ireland } \\
1 \text { Medical Research Centre }\end{array}$ & $\begin{array}{l}\text { As above } \\
+ \\
\text { Aerospace }\end{array}$ \\
\hline
\end{tabular}

In the second study [3], undertaken between 1994/5, attempts were made to contact the firms who had participated in the original collaborations and further interviews were conducted with 18 of 
these firms. In the majority of cases where contact was not made, this was because firms had gone out of business. These firms were revisited to assess longer term outcomes of the original collaborations. Two additional firms were interviewed about their long-term collaborations in order to maintain a range of types of collaboration.

The first study concentrated on an analysis of firms' motivations, the conduct of partnerships, factors associated with success or failure of the collaboration, and related policy issues; the second concentrated on which factors had contributed to the continuance or not of the collaboration, what firms' had learned from their experiences, and what this meant for future collaborations. Of particular interest for this paper's focus, was whether firms had extended the geographical scope of their interactions.

\section{Main Findings From Cases}

In the second study, we found that four firms had given up collaborating. In two this was associated with technical failures by their partners; the third had recognised that there are better, more comfortable strategies of gaining access to technical information. Six collaborations had continued over the whole period with the original partners. The two other firms had continued to collaborate but with different partners. At the time of the first study, most were collaborating with partners in UK. Some collaborations were local but most were no more than 100 miles apart e.g. between London and Cambridge, Oxford and Bristol. By the time of the second study, most were involved in international collaborations. Three, two scientific instruments companies and one Design Company had begun international collaborations. One of the former has developed links with a firm in the US; the others were with firms in Europe. Only one (not one of the six continuing collaborations), an instrumentation company, has had European (Eureka) funding to support the collaboration.

\section{Continuing collaborations}


The six collaborations were geographically diverse. Three were within UK and partners were local to each other, three were international ( see Table 3 below ). The international case studies reflect UK specialisations which provide opportunities for small high-tech firms in biotechnology, lasers, and nuclear instrumentation sectors to collaborate with large firms in other countries. Two of the three overseas collaborations involved UK biotechnology firms and US and European pharmaceutical companies. One of the biotechnology firms has increased the range of its collaborations and now had arrangements with German and French pharmaceutical companies.

\begin{tabular}{|l|l|}
\hline Types of Firms Involved & Nature of Partnership \\
\hline $\begin{array}{l}\text { 1.Large UK Vending Machine } \\
\text { Manufact'r } \\
\text { Small Design Consultancy }\end{array}$ & $\begin{array}{l}\text { Design of new components } \\
\text { Local collaboration (c. 30 miles) }\end{array}$ \\
\hline $\begin{array}{l}\text { 2. Small Software House } \\
\text { Large UK Retail Chain }\end{array}$ & $\begin{array}{l}\text { Development of stock ordering system. } \\
\text { Local collaboration (London) }\end{array}$ \\
\hline $\begin{array}{l}\text { 3. Small Instrumentation firm } \\
\text { Medical Research Centre }\end{array}$ & $\begin{array}{l}\text { Design/manufacture of new equipment } \\
\text { Local collaboration (London) }\end{array}$ \\
\hline $\begin{array}{l}\text { 4. Small UK nuclear instrumentation firm } \\
\text { Large French instrumentation firm }\end{array}$ & $\begin{array}{l}\text { Design modifications to equipment } \\
\text { International collaboration } \\
\text { (Oxford/Provence) }\end{array}$ \\
\hline $\begin{array}{c}\text { 5. Small UK biotechnology firm } \\
\text { Large US pharmaceutical firm }\end{array}$ & $\begin{array}{l}\text { New drug development, } \\
\text { International collaboration } \\
\text { (SE England/New York) }\end{array}$ \\
\hline $\begin{array}{c}\text { 6. Small UK biotechnology firm } \\
\text { Large US/European Pharmaceutical }\end{array}$ & $\begin{array}{l}\text { New drug development, } \\
\text { International collaboration } \\
\text { firm }\end{array}$ \\
\hline
\end{tabular}

\section{Table 3: The Six Continuing Collaborations}

In four cases involving small firms, the partnerships were kept active and productive by the persistence of the small firm owner/managers, in the face of frequent changes of personnel in their larger firm partners. One of the interesting developments is that in two continuing relationships there has been a change from "head-to-head" research collaborations to a mature supplier/agent relationship. The character of these enduring collaborations can best be illustrated by briefly 
sketching some of their responses to difficulties encountered as well as the gains to the partners, identifying the critical factors.

In a partnership between the vending machine manufacturer and a small engineering design house, the critical factors were compatibility, commitment, communications and common aims. The collaboration has been successful for both partners primarily because of the high level of trust developed between individuals. The outcome has been the design of a system for a sophisticated vending machine. The machine is now in general use throughout the UK, although modifications to the design are still being carried out. In this collaboration, both sides continued to work together even though the 'product champion' in the larger firm had taken early retirement and was now working as a consultant to his former employer. However, this person had to both convince his successor of the value of the smaller firm, and sell the merits of the system. Once this had been achieved, opportunities were created for the small partner to be introduced into other markets in Europe with the same partner.

As a result of the successful early stages of the collaboration, the larger firm had learned to use the expertise of the small firm at early stages of other new products (for example to contribute to brain-storming sessions) rather than just at the problem solving stage. For the small firm, the most significant learning process was recognising the value of institutionalised communication systems with other partners located throughout the UK to discuss issues openly with these partners. The small firm said,

"we sell our ability to work with clients to new clients. We show that we are willing to work with in-house engineers on projects".

In this case, the geographical context was one of proximity. The relationship between the small firm and the larger firm was facilitated by ease of access which enabled the small firm to acquire knowledge of the partner firm's technical needs, organisational culture, market strategies, and the appropriate technical standards for that product. This provided the a means of extending spatial scales at which it collaborated. It was selling itself as a good collaborator. The recognition of the importance of a 'common language' developed as a communication skill, provided increased flexibility as a competitive advantage. This practice has overcome the perennial UK problem of a 
business culture which inhibits collaboration.

The second example illustrates the critical factors of national context, control, communication and shows how a mismatch of expectations and commitment can lead to problems in collaboration. The collaboration involved a small UK nuclear instrumentation firm and a major French instruments company in the south of France. The UK firm had originally sought out potential partners on mainland Europe and had been fortunate that the French firm had been looking to enter the UK market. The relationship required considerable cultural and organisational adjustment for the small UK firm. This was not matched by any significant adaptation on the part of the much larger partner.

At the first interview the respondent explained how it had been necessary to come to terms with the French partner's rather lax attitude towards meeting UK national standards. In other words, there was no common understanding of regulatory processes. Moreover, in spite of the match of interests for both sides, the asymmetry in the power relationships, and the differences in degree of dependency meant that the UK firm had to continually reinforce its position with the principal in order to maintain a position of priority in that company's concerns. This was being made more difficult by continual personnel changes in the French partner. Cultural and geographical distance was overcome by frequent faxes, telephones calls, and regular visits to France. In this example the international and national context mattered from the point of view of regulating the conduct of the collaboration. The small UK firm had to establish its own participatory conventions to establish some form of norm of co-operation.

In the case of two long-term transnational collaborations involving biotechnology firms and pharmaceutical companies, the critical factors of contingency, control and commitment had been dealt with effectively, while in one case, the smaller firm had to deal with problems of compatibility. In these two cases personnel on both sides had changed during the lifetime of the partnership. These firms had developed management systems which enabled the partnership to flourish in spite of differences in culture and resources between biotechnology firms and their much larger, foreign partners. The conventions of collaboration consisted of institutionalised high levels of communication through which different types of knowledge (technical, market, 
organisational, regulatory) were updated.

The collaboration between a small UK biotechnology company and a large US pharmaceutical company was originally set up because it brought together complementary sets of expertise. The UK division of the pharmaceutical company undertakes development but basic research is done in the USA. At the time of the first study, strenuous efforts had been made by a 'product champion' in the UK arm of the US firm to circumvent the cultural rigidities in the system in order to get the collaboration accepted by the US parent. At the time of the second study, in spite of the collaboration having lasted for over six years, the respondent from that firm said that the group in the USA were still not used to collaboration. Moreover, the company did not document and formalise what had been learnt. Further unpredictability was introduced into the relationship because of the potential risk caused by changes in the structure of the partner company. The small UK firm feared being discarded as the US partner had recently acquired a US-based biotechnology firm.

This example highlights the significance of the national context. The pattern is consistent with Storper's finding that managerial practices in large American firms are consistently more oriented towards imposing very rigid and hierarchical role distinctions and limited information feedback compared to Japanese or German firms [7]. In this example the ability of the small UK firm to collaborate at this spatial scale was predicated upon its ability to develop its in-house range of all five types of knowledge of its partner's operations even though these were not matched by an equivalent learning process on the part of the US firm.

\section{Collaborations with Different Partners}

The next two example of learning through bitter experience concerns two small UK instrumentation firms. Here the critical factors are control and contingency. In the first a small scientific instruments firm which had had, at the time of the first visit, a number of collaborations, 
many of them failures. Nearly all of the failures had involved the electronics research and manufacturing divisions of major UK corporations. Another had been with a small UK firm which had gone out of business. Although the entrepreneur had good knowledge of the technical and market needs of his partners, crucially he had failed to develop in time an understanding of corporate culture in the UK. He had found that he was unable to control the conduct of technical relationships, being on the receiving end of decisions taken without regard to his circumstances. In one case, he was not allowed to advertise the technical success of a machine developed in conjunction with a UK aerospace company even though the project had absorbed much of the firm's resources. When the aerospace firm decided not to extend the initial order he was unable to capitalise on the technical advance because the market was confined to this one purchaser.

By the time of the second interview it was clear that the owner-manager had adapted his behaviour to overcome the difficulties he had experienced. Two significant changes to the firm had occurred. The first was that the firm had moved into manufacturing rather than supplying specialist research services. The second was the appointment of a non-executive director responsible for financial planning. These changes had altered the firm's approach to collaboration as there was now more emphasis on co-operation over product development than on pure research. Collaboration was still seen as a driving force for the firm's future development but with decisions being based on strategic criteria rather than on scientific merit alone. More resources had been allocated to dealing with the geo-cultural conditions under which collaboration occurs. The firm is currently engaged in two further, and apparently successful, collaborations, one with the Swiss division of a major US computer firm, the other with the University of Florida. This firm had chosen to forego regional/national collaboration in favour of more geographically extensive but more culturally compatible business relationships.

The next example illustrates most of the critical factors: control, contingency, contracts, communications and context. In this case the victim was a small high-tech firm which is a world leader in the manufacture of specialist lasers. The firm had experienced many failures in collaboration. One expensive failure was within a EUREKA consortium set up to develop different types of lasers. The small firm had expected to market the technology with its larger, German partner but found it had lost its expertise to this firm. The German firm had flouted the 
conventions of the European programme and had organised the exploitation of the intellectual property in Germany outside of the partnership agreement which defined common aims. The cost to the UK firm was 5 lost years of project development. The UK firm recognised that,

"We were somewhat naive when we went into the project and didn't tie up details in an enforceable contract that would have prevented them from doing this sort of thing".

In spite of this experience and because of the specialist market, the firm has no option but to build long-term relationships with major businesses overseas. It has had to develop conventions of identity and participation with non-UK partners. It had been successful in this having developed a successful collaboration with a US company in Texas.

\section{Other collaborations}

Even with international partnerships between more equal partners (in terms of size), collaborations require senior staff to travel long distances in order to sustain a common collaboration language. Two examples illustrate the necessity of communication to establish mutual behavioural expectations on which conventions of participation are based and to overcome national cultural differences.

The first collaboration was between UK and Australian firms (on software development for the commercial airline industry). In this case, senior technical people regularly travelled to Australia in order to talk through the implementation of the software design. In addition, teleconferencing was regularly used between the partners but was not seen as an efficient method of communicating. This was because the agenda set for the televisual link was not necessarily the one which primarily concerned the people in Australia.

The second was between a firm in Northern Ireland and one in the USA, with a further partner in Canada. The collaboration was the design and production of a small commercial aeroplane. The practice and routine in this example took the form of regular meetings. This involved a senior manager from the UK visiting the partner firm in the USA for only a three hour meeting before returning to the UK. This event occurs two or three times a month. Such frequent interactions are beginning to overcome cultural barriers, such as those caused by differences in sense of humour 
and ways of thinking. The Canadian team found the Irish sense of humour difficult to understand. They thought that levity was misplaced in discussions about a major international development valued at multi-billions of dollars.

In these two collaborations, the critical factor was communication. Personal contact was required for issues to be resolved face-to-face. The examples illustrate how a process for making key decisions was established and allowed people to interpret nuances in conversation hidden by the fog of cultural differences. Technical learning is therefore complemented by personal interaction which establishes norms of co-operation. This appears to be particularly important for successfully managing partnerships overseas.

\section{Evaluation}

The case studies have been analysed in relation to a set of critical factors which could govern firms' expectations and actions over the conduct and outcome of inter-firm collaboration. They show that by far the most important of these is communications. It is clearly a necessary requisite but by itself is insufficient to overcome the problems of lack of control faced by small firms, especially those in collaborations with larger firms. Most of the small firms in the study have been the driving force in building relationships with the larger firms, establishing common bodies of knowledge, the basis of conventions, as a means of protecting their interests. The example of a collaboration involving the small laser firm which failed shows how formal, managed collaborations as opposed to individual initiatives, may expose small firms to risk where their technology is visible to other firms, and where control over final market is at arm's length. This example is interesting from two other points of view. First is in that it is contrary to the stereotype portrayed in the earlier about the implied reliability of German firms as collaborators. The case studies of the other collaborations between large companies also show that the communication is the critical factor in successful collaboration between firms in different geographical contexts.

Our approach has combined organisational with geographical/social interpretations of inter-firm behaviour which possibly under-plays the risks involved and the necessity for frequent interaction. 
The study helps explain what is meant when its claimed in other studies [38] that distance is not a problem in the conduct of inter-organisational activity. First, the reality is that frictions of distance have been largely overcome by the allocation of resources designed to facilitate the free flow of information (preparation, time, travel and information technology). Second, firms or individuals have learnt about the norms of behaviour of other firms in other places, either within or outside their own national innovation system. We have shown how geo-cultural defined differences are components of broader national institutional differences. These examples have both illustrated the problems for small firms working within the sometimes hostile environment of a collaboration within a large firm even within the same country, and how a product champion in a large firm can produce a more responsive culture within the company's operational framework. They have also indicated the lengths which small firms have to go to acquire the different kinds of knowledge which will sensitise them to the dangers inherent in collaborating with non-domestic partners. In all cases, the specificities of the geo-cultural context required firms to adapt their organisational practices in order to come out as winners from collaboration. For some firms the combination of pressures to adapt and the experience of loss of control were too great for collaboration as a strategy to be continued.

\section{Conclusions}

We have sought to identify how the national and international regulatory environment influences the establishment conventions of collaboration based on common bodies of knowledge. Storper's concept of conventions (acknowledged and shared rules) and Lorenz's identification of different types of knowledge are used to discuss how learning in a spatial context involves adapting to geographical, cultural, economic and political realities. We have shown that in successful collaborations different types of knowledge form the basis of the critical factors which are implicated in firms' capacity to interpret past and current behaviour. These become a means of efficient screening of new opportunities, distinguishing between technical and market potential of joint developments; predicting the possibilities of new markets through using their partner's own market intelligence; assessing the risks of collaboration arising from their own and partner's weaknesses and differing priorities; negotiating intellectual property rights; and redressing the power imbalances between small and large firms. Through these learned capabilities, firms 
negotiate with partners to establish 'identities of collaboration' in which both there is some common acceptance of rules of conduct. The resulting new conventions or norms of co-operation facilitate interaction whatever the distance between partners.

However, while the need to overcome cultural and size disparities produced demands on the ability of smaller partners to institutionalise more balanced sets of power relations through the establishment of a common cultural base of participation as shared conventions. However, even international collaborations under EC programmes which have their own rules of engagement require the means of ensuring that risks are minimised. Formal agreements are not substitutes for firms' understanding of the dangers of relying on trust to safeguard their interests. Failure to learn may mean that the geographical outcomes of this form of collaboration are not necessarily those intended. The basis of these programmes is the sharing of information as form of collective order. The example of the small laser firm shows this breaks down because there are no institutionalised controls, and larger firms can exploit asymmetries of power.

The theoretical implications of this study are that we have identified a combination of sociopolitical and geo-contextual dimensions to the conduct of inter-firm collaboration. These produce geographically specific sets of power relations in which smaller firms seek to redress the balance of power with larger firms by promoting acknowledged and shared rules. This goes beyond what is commonly referred to as 'trust' We find that the notion of trust in commercial relationships may be overplayed if it does not take account of the essentially transactional nature of collaboration. On the other hand, trust, especially at a professional scientific level is often the basis of much informal collaboration.

From this point, the advice for small firms in particular and for firms in general is not to trust your partner. The role for policy is to provide the means of helping firms identify which critical factors are likely to be the most significant in the way a collaboration, particularly with overseas partners will proceed. These are based on an assessment of which types of knowledges are required in order facilitate harmonious realtionships. For example, what do firms needs to know about the other firm's priorities, technical competences, their potential weaknesses and so on. 
Acknowledgements: - The financial support of the Economic and Social Research Council's "European Context of UK Science Policy" Research Initiative (Grant number L3235014) is acknowledged.

\section{References:}

1. Moore, B (1996) 'Sources of Innovation, Technology Transfer and Diffusion' in The Changing State of British Enterprise: Growth, Innovation and Competitive Advantage in Small and Medium Sized Firms 1986-95, ESRC Centre for Business Research, Department for Applied Economics, University of Cambridge, September 1996

2. Dickson K, Lawton Smith H \& Smith S, (1991), "Bridge over troubled waters: Problems and opportunities in inter-firm research collaboration", Technology Analysis and Strategic Management, 3 (2), pp 143-156.

3. Dickson K, Coles A-M \& Lawton Smith H, (1997), "Staying the Course: Strategic Collaboration for Small High Tech Firms", Small Business and Enterprise Development Journal, 4(1).

4. George, V.P (1995) 'Globalisation through inter-firm co-operation: technological anchors and temporal nature of alliances across geographical boundaries', International Journal of Technology Management, 10, (1), pp 131-145.

5. Keeble, D Lawson, C Lawton Smith, H, Moore, B and Wilkinson, F (1997) 'Internationalisation processes and networking and local embeddedness in technologyintensive small firms' ESRC Centre for Business Research, Cambridge University WP 53 March 1997

6. Swyngedouw, E (1997) Neither Global or Local: 'Glocalisation' and the Politics of Scale. In Cox K (Ed) The Global and the Local: Making the Connections Guildford/Longman, New York.

7. Storper, M (1993) 'Regional 'worlds' of production: learning and innovation in the technology districts of France, Italy and the USA’ Regional Studies 27, 5 433-456

8. Lorenz, E (1992) 'Trust, Community and co-operation: towards a theory of industrial districts' in Pathways to Industrialisation and regional development ed M.Storper and A.Scott, 
London: Routledge, 195-204

9. Howells, J and Green, A E (1986) 'Location, technology and industrial organisation in UK services' Progress in Planning 27

10. Nelson, R and Rosenberg, N (1993) 'Technical Innovation and National Systems' in Nelson, R (ed) (1993) National Innovation Systems: A Comparative Analysis, Oxford: Oxford University Press.

11. Teece, D (1986) 'Profiting from technological innovation: Implications for interaction, collaborative licensing and public policy' Research Policy 16 (6) 285-305

12. Malecki, E and Todtling, F (1995) 'The New Flexible Economy: Shaping Regional and Local Institutions for Global Competition' in C.S Bertuglia, M.M. Fischer and G. Preto (eds) Technological Change, Economic Development and Space, Springer, Berlin, New York

13. Szarka (1990) 'Networking and Small Firms' International Small Business Journal 8 (2), pp $10-22$.

14. Hippel, Von E (1978), "Users as Innovators", Technology Review, 80 (3), p 30-34.

15. Malecki, E.J. and Tootle, D M (1996) 'Small manufacturers in Flexible Networks Examples from the US Wood Products and Metal Products Sectors' Paper prepared for presentation at the Annual Association of American Geographers, Charlotte April 1996

16. Ahern, R (1993) 'The Role of Strategic Alliances in the international organisation of industry' Environment and Planning A 25 1229-1246

17. Hamill, J (1989) "Strategic alliances - A distinctive form of international activity" Paper presented at Acquisition Monthly Conference on Strategic Alliances: An Alternative Way Ahead, London.

18. Lawton Smith, H (1991) 'Industry and Academic Links: The Case of Oxford University', Environment and Planning C, Vol. 20 No. 4, 1991, pp 405-416.

19. Bonaccorsi, A and Piccagula, A (1994) 'A Theoretical Framework for the Evaluation of university-industry relationships' $R \& D$ Management 24 (3) 229-247

20. Maskell, P and Malmberg, A (1995) 'Localised learning and industrial competitiveness" Paper presented at the Regional Studies Association Conference on "Regional Futures', Gothenburg, Sweden, May 1995

21. Sayer, A and Walker, R, (1992) The New Social Economy: Reworking the Division of Labour, Blackwell, Oxford. 
22. Hakanson, L (1993) "Managing co-operative research and development: partner selection and contract design", R\&D Management, 23, (4) pp 273-285.

23. Dekker, D 'Large Company Involvement with SMEs: A European Survey' In DGXIII - and TII European Association for the Transfer of technologies, Innovation and Industrial Information (eds) Partnership between Large and Small Firms: Proceedings of the conference Held in Brussels 13 and 14 June 1988, Graham and Trotman, London 1990.

24. Doz, Y (1988) 'Technology partnerships between larger and smaller firms: some critical issues' in F. Contractor and P. Lorange (eds) Cooperative Strategies in International Business Mass: Lexington 317-337

25. Dodgson, M (1993) Technological collaboration in industry, strategy, policy and internationalisation in innovation Routledge, London

26. Asheim, B and Dunford, M (1997) 'Regional Futures' Regional Studies 31 (5) pp 445--456

Bennett, R (1997) ‘Administrative systems and economic spaces’ Regional Studies 31 (3) $323-336$

27. Ettlinger, N 'The Localisation of Development in Comparative Perspective' Economic Geography 66 pp 67-82

28. Gertler, M (1997) 'The Invention of Regional Culture' in R.Lee and J. Wills (eds) Geographies of Economics London:Arnold

29. Pavitt, K (1984) "Sectoral patterns of technical change: Towards a taxonomy and a theory" Research Policy 13 (1984) pp 343-373.

30. Archibugi, D and Michie, J (1995) 'The globalisation of technology' Cambridge Journal of Economics 19 (1) 121-140

31. See for example:- Wiendt A \& Amin N (1994), 'Biotechnology: The emerging battlefield for US and Japanese Pharmaceutical Companies', Technology Analysis and Strategic Management, ; Webster, A and Swain J (1991) 'The pharmaceutical industry: Towards a new Innovative Environment' Technology Analysis and Strategic Management, 3 (2), pp 127-142; Bower, J.D and Whittaker, E (1993), "Global R\&D networks: the case of the pharmaceutical industry", Journal of Industry Studies, 1 (1), pp 50-64.

32. Chesnais, F. (1993), The French National System of Innovation Ch 6 pp 192-229 in R. Nelson. (ed) (1993), National Innovation Systems: A Comparative Analysis New York and Oxford: OUP. 
33. Cohen, W. M and Levinthal, D. A (1990), "Absorptive capacity: a new perspective on learning and innovation", Administrative Science Quarterly, 35, pp 128-152.

34. See for example:- Porter, M.E (1990) The Competitive Advantage of Nations London: Macmillan; Mason, G and Wagner, K 'Innovation and the Skill Mix: Chemicals and Engineering in Britain and Germany’ National Institute Economic Review May 1994 6172; Gertler (1997), op. cit.

35. As noted in Teece, D (1988) 'Technological Change and the Nature of the Firm' in G.Dosi,C.Freeman,R.Nelson, G.Silverberg, and L.Soete (eds) Technical Change and Economic Theory Pinter, London.

36. Walker, W (1993) "National Innovation Systems: Britain", in Nelson, R (ed) (1993) National Innovation Systems: A Comparative Analysis, Oxford University Press, Oxford.

37. Soskice, D (1997) 'German Technology Policy, Innovation and National Institutional Frameworks' Industry and Innovation 4 (1) 75-96

38. Hughes, K and Christie I (1994) UK and European Science Policy: the role of collaborative research London: Policy Studies Institute 